
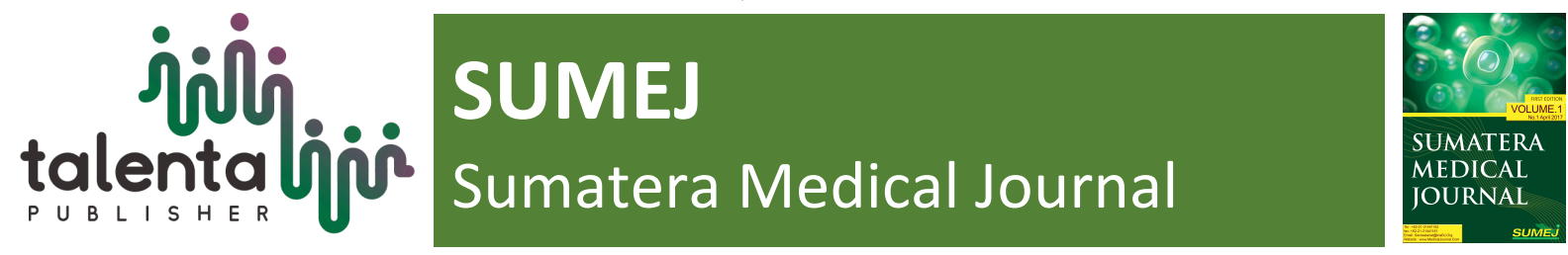

\title{
Quality of Life Assessment in Skin Tag Patients
}

\author{
Imam Budi Putra ${ }^{1}$, Nelva Karmila Jusuf ${ }^{1}$, Johan Kartayana ${ }^{1}$ \\ ${ }^{I}$ Departement of Dermatology and Venereology Faculty of Medicine Universitas of Sumatera Utara \\ Adam Malik General Hospital Medan, North Sumatera, Indonesia
}

\begin{abstract}
Background Patients with skin disease may experience clinical symptoms, such as itching, pain, and discomfort, that can have a negative impact on quality of life (QOL). Skin tag is a common benign tumor of the skin with small, soft pedunculated protrusion, it commonly occures in axilla, neck and major flexura area, despitethe lesion usually asimptomatic, sometimes patients complain about cosmetics appereances, itching or discomfort experienced. Objective: The aim of our study was to assess the impact of skin tag lesion on quality of life of patients. Method: This is a descriptive study with a cross sectional design, involving 50 patients with skin tag lesion who visited the Dermatology outpatient clinic Adam Malik General Hospital, Medan from September 2016 to October 2016. The patients were filled Indonesian version of skindex-29 questionnaire to measures the effects of skin disorders on their QOL. Result: In this study QOL in skin tag patient was fairly good, 38(76\%) subjects had a skindex-29 category score $<5$, and $12(24 \%)$ subjects had a skindex-29 score 6-17. We didn't findimpaired QOL in all skin tag patients. Conclusion: In this study's we concluded skin tag does not affect the quality of life of the patients.
\end{abstract}

Keyword: Quality of life, skin tag, Skindex-29

Received 30 May 2018 | Revised 10 July 2018 | Accepted 25 September 2018

\footnotetext{
* Corresponding author at: Faculty of Medicine, Jalan Doktor Mansyur No.5 Kampus USU Padang Bulan, Medan, Sumatera Utara 20155
} 


\section{Introduction}

Skin tag is a common benign skin lesion composed of loose fibrous tissue and occurring mainly on the neck and major flexures as a small, soft, pedunculated protrusion [1,2] . The incidence of skin tag in general population is may vary from $20-25 \%$, usually affect middle aged individually and the elderly. 3 There is no difference in incidence of skin tag between male and female $[3,4]$.

The cause of skin tag is still unclear, although friction, obesity, pregnancy, aging, diabetes mellitus, hyperinsulinemia, and family history have been proposed as potential aetiological or associated factors. Skin tag usually a simptomatic, but sometimes lesions can become irritated or subject frequent complaints in dermatology clinics for esthetic reasons or due to traumatism resulting from contact with clothing or jewelery does can affect the quality of life in skin tag patients $[5,6]$.

Skin disorders are generally considered trivial and the patient distress and impact on quality of life is largely ignored. The effect of dermatological disease can vary from minor to severe handicap. The skin disorder may cause disturbances in occupation, recreation, selfimage, discrimination, embarrassment, and depression [7].

The measurement of health-related quality of life (HRQOL) is increasingly important in patients withskin diseases [8]. Health-related quality of life (HRQL) reflects patients' evaluation of the impact of disease and treatment on their physical, psychological, and social functioning and wellbeing. The Skindex is a health-related quality of life (HRQOL) instrument designed to measure the effects of skin disease on patients lives. This dermatology-specific questionnaire has been extensively studied and refined in different population samples, furthermore skindex has been used to study the effects of a wide variety of skin conditions on patients lives $[9,10]$.

The Skindex is an instrument that measures the effects of a skin disease on a patient's QoL, and has been refined and studied extensively [11]. It is a self-administered questionnaire that was originally created in English. It initially included 61 questions but was then modified to 29 questions[12], in this study we aimed to assess quality of life in skin tag patient using skindex29.

\section{Methodology}

This study is an observational study with cross sectional design conducted at Department Dermatology and Venereology Adam Malik General Hospital, Medan from September 2016 until October 2016. All skin tag patients underwent an anamnesis, physical and dermatological examination. The clinical diagnosis of skin tag based on researchers and advisor, the type of lesion (sessile, sessile and mixed type (combination pedunculated and non-pedunculated), the number of lesions (single or multiple) and the location (flexure and non-flexure area) of skin tag was recorded. 
All subjects in this study were signing the informed consent voluntarily, furthermore subject do questionnaires assisted by researcher to assess the quality of life by using Skindex-29. The questions are consisting of 29 questions, divided into three main criteria: symptoms, functioning and emotions. The collected then processed and presented descriptively.

\section{Results and Discussion}

Fifty subjects with skin tags were offered and assessed to fill the skindex-29 questionnaire. Characteristics of the subjects in this study are shown based on patient sociodemographic and characteristics of skin tags lesion include gender, age, education level, occupation, family history, duration of skin tag, and clinical picture of skin tag lesion (Table 1). Total from 50 subjects enrolled in this study, 33 (66\%) subjects were female and 17 (34\%) subjects were male, 46 (92\%) subjects were married. The age distribution of subjects in this study majority in the age group 4049 years $(36 \%)$. Duration of skin tag varied from 1 years to 15 years, whereasmajority in the group $1-5$ years $(58 \%)$.

Table 1. Demographic Characteristic of Skin Tags Patient

\begin{tabular}{lcc}
\hline Variable & $\mathbf{n}$ & \% \\
\hline Gender & 17 & 34 \\
Male & 33 & 66 \\
Female & & \\
Usia & 4 & 8 \\
$20-29$ years & 7 & 14 \\
$30-39$ years & 18 & 36 \\
$40-49$ years & 16 & 32 \\
$50-59$ years & 4 & 8 \\
$60-69$ years & 1 & 2 \\
$70-79$ years &
\end{tabular}

\section{Marital status}

Single

Married

\section{Education}

Elementary Junior high

school

Senior high

school

University

Occupation

Goverment

employees

Private

employees
34

66

14

36

8

2 


\begin{tabular}{lcc} 
Enterpreneur & 11 & 22 \\
Students & 1 & 2 \\
unemployment & 12 & 24 \\
\hline
\end{tabular}

Table 2. Characteristic of Skin Tag Lesion

\begin{tabular}{lcc}
\hline Variable & n & \% \\
\hline Duration of skin tag & & \\
1-5 years & 29 & 58 \\
6-10 years & 18 & 36 \\
$11-15$ years & 3 & 6
\end{tabular}

Tipe skin tag

$\begin{array}{lcc}\text { Pedunculated } & 10 & 20 \\ \text { Non pedunculated } & 18 & 36 \\ \text { Mixed type } & 22 & 44 \\ \text { Number of skin tag } & 9 & 18 \\ \text { Single } & 41 & 82 \\ \text { Multiple } & & \\ \text { Location } & 44 & 88 \\ \text { Flexure area } & 6 & 12 \\ \text { Non-fluxure area } & \end{array}$

Distribution quality of life scores in this study showed 38 (76\%) subjects had a very high quality of life and $12(24 \%)$ subjects had a high quality of life and we didn't find a moderate or low quality of life score in all subjects (Table 2), furthermore based on the characteristics of the skin tag lesions we also didn't find a significant difference in the quality of life score from all subject (Table 4).

Table 3. Quality of Life Scoring

\begin{tabular}{lcc}
\hline Skindex-29 & n & $\mathbf{\%}$ \\
\hline Score category & & \\
$<5$ (Very high) & 38 & 76 \\
$6-7$ (High) & 12 & 24 \\
$18-36$ (average) & 0 & 0 \\
$>37$ (low) & 0 & 0 \\
\hline
\end{tabular}


Table 4. Distribution Category of Quality Of Life

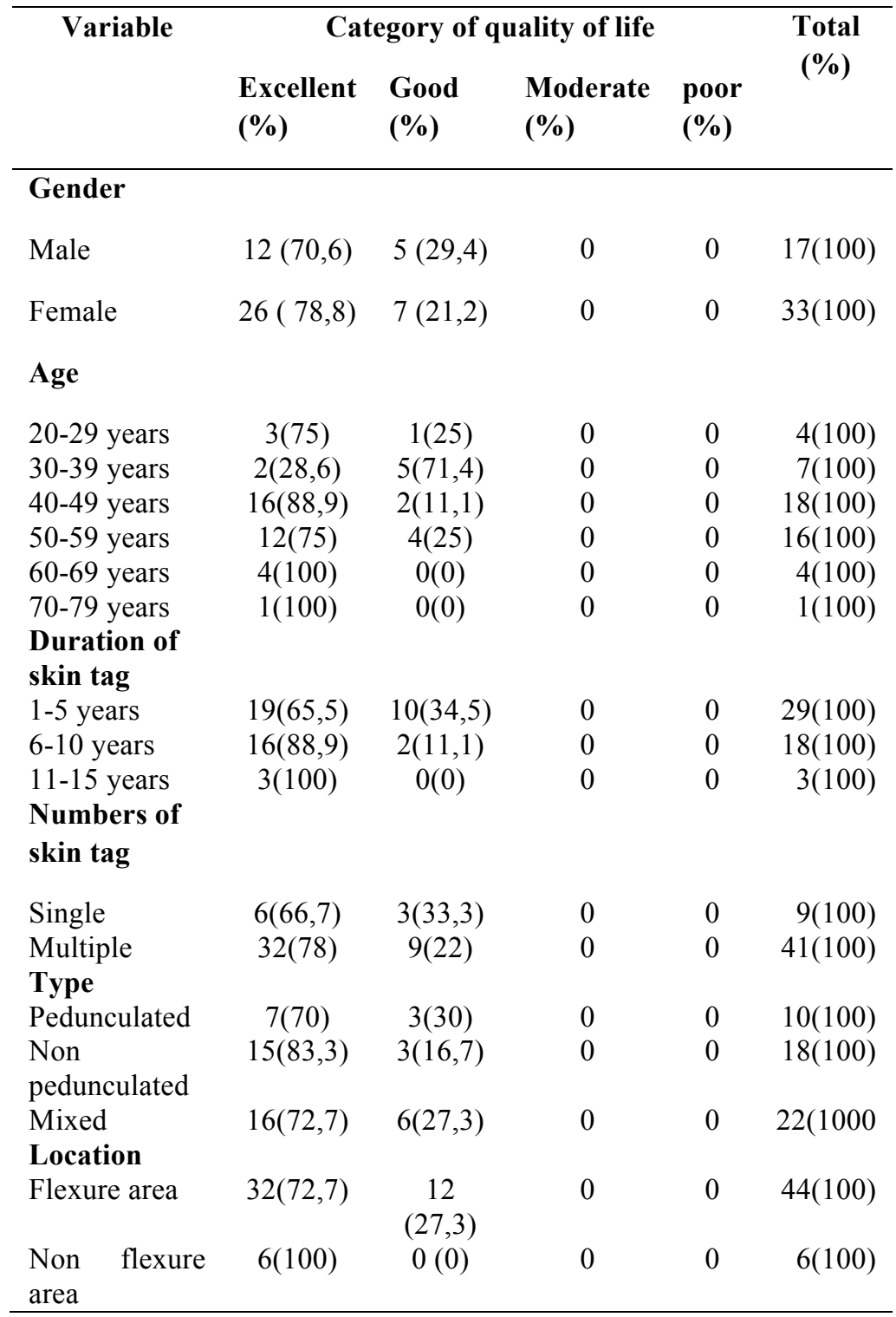

\section{Discussion}

It has now been determined that quality of life impact of certain skin disorders can be at a magnitude of several systemic disorders like diabetes mellitus and chronic renal disease7The measurement of health-related quality of life (HRQOL) is increasingly important in patients with skin diseases. Despite the availability of a variety of instruments and new psychometric techniques, there is no consensus as to which HRQOL instruments are to be preferred in dermatology 8HRQOL reflects patients' evaluation of the impact of disease and treatment on their physical, psychological, and social functioning and wellbeing [13].

The concept of QOL was developed from an array of information about physical, social and psychological well-being; it was fostered by the World Health Organization's broad view of health as not merely the absence of disease or infirmity, but the ability of a person to lead a productive and enjoyable life. Skin disease has been recognized as having a detrimental effect on 
the QOL of patients. This psychosocial aspect of skin disease has important implications for the optimal management of patients [8].

The Skindex-29 is among the most commonly used dermatology-specific, health-related quality of life (HRQOL) instruments. The excellent psychometric features of the Skindex-29, including factor structure, have been confirmed by multiple studies [14]. Skindex-29 is one of the HRQOL instruments that comprehensively designed to measure the effects of skin disease suffered in daily life of patient $[10,14]$. In Skindex-29 questionnaire consists of 29 questions combinations of clinical symptoms, emotions and functioning [13]. Skindex scores are reported as three-score scale, related to the three domains; a higher score indicate the lower level of quality of life $[11,15,16]$.

Skin tag or acrochordons is benign skin tumours commonly found in the general population. Skin tag generally asymptomatic and does not cause pain, but it can cause a cosmetic disorders and discomfort to the patient $[5,17]$, until now researchers didn't find any published study that measured the quality of life score in patient with skin tag, but there are a few studies which measured the quality of life scores in patient with benign skin tumours.

In a study conducted by Chren, showed patients with benign skin tumors have a good quality of life when compared with patients with other dermatological symptoms like psoriasis, acne, dermatitis, and verruca, so it can be concluded that patients with benign skin tumours is not bothered with the lesion[15]. Accordance with study conducted by Taborda et al, they also found similar results, patients with benign tumors of the skin generally have a high quality of life scores [18]. The results in this study is agreement with study conducted by Chren and Taborda who find the quality of life in skin tag patients is fairly good. It can be concluded the skin tag lesions does not affect the psychological and social life of the patient.

In this study we also found that there was no significant differentiation quality of life scores based on gender and age of the subject (Table 3). In a study conducted by Tejada et al in patients with skin disorders in southern Brazil, reveal that there was no significant differences in quality of life score both in male and female patient [19], this result contrast with the study conducted by Abolfotouh et al, they found a female patients have a lower quality of life scores compared with male patients, because women tend to care about their cosmetic appearances in a public [20]. Based on the age of patients, the results in this study also accordance with study conducted by Harlow et al and Al-Hoqail on patients with skin disease, they didn't any difference in quality of life score between the younger and older patients [21,22]. Contrast with other study conducted by Tejada et al, they found the older patient had a lower impact on quality of life compared to the younger patient. In this study based on the characteristics of skin tag lesion,we also didnt find asignificant differences in the quality of life score for all subjects (Table 4). 


\section{Conclusion}

The results of this study, showed patients with skin tag have a fairly good of quality of life, no subject has a moderate or poor quality of life. It can be concluded in this study, the skin tag lesions arising in patients does not cause impaired quality of life both psychologically and socially.

\section{REFERENCES}

[1] H. Kamino, J. Pui, Fibrous and fibrohistiocytic proliferations of the skin and tendons, Dermatology. Philadelphia: Elsevier. (2003) 1869.

[2] R. Sari, A. Akman, E. Alpsoy, M.K. Balci, The metabolic profile in patients with skin tags, Clinical and Experimental Medicine. 10 (2010) 193-197.

[3] E. Erkek, U. Kasi, Y. Bagci, H. Sezikli, Leptin resistance and genetic predisposition as potential mechanism in the development of Skin tag, Hong Kong J Dermatol Venerol. 19 (2011) 108-14.

[4] R. Banik, D. Lubach, Skin tags: localization and frequencies according to sex and age, Dermatology. 174 (1987) 180-183.

[5] A. de A. Tamega, A.M.P. Aranha, M.M. Guiotoku, L.D.B. Miot, H.A. Miot, Association between skin tags and insulin resistance, Anais Brasileiros de Dermatologia. 85 (2010) 2531.

[6] C.J. Ko, Dermal hypertrophies and benign fibroblastic/myofibroblastic tumors, Fitzpatrick's Dermatology in General Medicine. (2009).

[7] A. Ejaz, S.E. Rao, A. Manzoor, A. Niaz, Quality of life assessment in chronic skin disorders, Journal of Pakistan Association of Dermatology. 25 (2016) 86-89.

[8] H. Both, M.-L. Essink-Bot, J. Busschbach, T. Nijsten, Critical review of generic and dermatology-specific health-related quality of life instruments, Journal of Investigative Dermatology. 127 (2007) 2726-2739.

[9] T.E. Nijsten, F. Sampogna, M.-M. Chren, D.D. Abeni, Testing and reducing skindex-29 using Rasch analysis: Skindex-17, Journal of Investigative Dermatology. 126 (2006) 12441250 .

[10] T.E. Nijsten, F. Sampogna, M.-M. Chren, D.D. Abeni, Testing and reducing skindex-29 using Rasch analysis: Skindex-17, Journal of Investigative Dermatology. 126 (2006) 1244 1250.

[11] K. Janowski, S. Steuden, B. Bereza, The Polish version of Skindex-29: psychometric properties of an instrument to measure quality of life in dermatology, Advances in Dermatology and Allergology/Postępy Dermatologii i Alergologii. 31 (2014) 12.

[12] M.A. Abolfotouh, M.S. Al-Khowailed, W.E. Suliman, D.A. Al-Turaif, E. Al-Bluwi, H.S. Al-Kahtani, Quality of life in patients with skin diseases in central Saudi Arabia, International Journal of General Medicine. 5 (2012) 633.

[13] C.A. Prinsen, R. Lindeboom, M.A. Sprangers, C.M. Legierse, J. De Korte, Health-related quality of life assessment in dermatology: interpretation of Skindex-29 scores using patientbased anchors, Journal of Investigative Dermatology. 130 (2010) 1318-1322.

[14] T. Nijsten, F. Sampogna, D. Abeni, Categorization of Skindex-29 scores using mixture analysis, Dermatology. 218 (2009) 151-154.

[15] M.-M. Chren, The Skindex instruments to measure the effects of skin disease on quality of life, Dermatologic Clinics. 30 (2012) 231-236.

[16] C.A. Prinsen, R. Lindeboom, M.A. Sprangers, C.M. Legierse, J. de Korte, Health-Related Quality of Life Assessment in Dermatology: Interpretation of Skindex-29 Scores Using Patient-Based Anchors., Journal of Investigative Dermatology. 130 (2010). 
[17] K. Wolff, R.A. Johnson, Fitzpatrick's color atlas and synopsis of clinical dermatology, McGraw Hill, 2009.

[18] M.L. Taborda, M.B. Weber, K.A.M. Teixeira, A.P. Lisboa, E. de Q. Welter, Evaluation of the quality of life and psychological distress of patients with different dermatoses in a dermatology referral center in southern Brazil, Anais Brasileiros de Dermatologia. 85 (2010) $52-56$.

[19] S.C. Tejada, R.A. Mendoza-Sassi, J.H. Almeida, P.N. Figueiredo, V.F. Tejada, Impact on the quality of life of dermatological patients in southern Brazil., Anais Brasileiros de Dermatologia. 86 (2011) 1113-1121.

[20] M.A. Abolfotouh, M.S. Al-Khowailed, W.E. Suliman, D.A. Al-Turaif, E. Al-Bluwi, H.S. Al-Kahtani, Quality of life in patients with skin diseases in central Saudi Arabia, International Journal of General Medicine. 5 (2012) 633.

[21] D. Harlow, T. Poyner, A.Y. Finlay, P.J. Dykes, Impaired quality of life of adults with skin disease in primary care, British Journal of Dermatology. 143 (2000) 979-982.

[22] I.A. Al-Hoqail, Impairment of quality of life among adults with skin disease in King Fahad Medical City, Saudi Arabia, Journal of Family \& Community Medicine. 16 (2009) 105. 